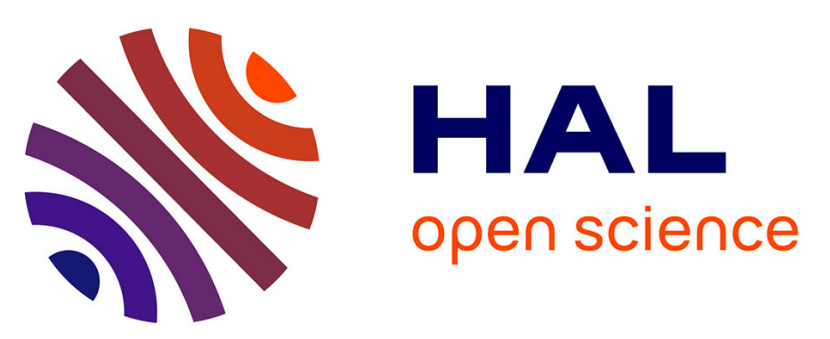

\title{
Coenzyme Q10 supplementation lowers hepatic oxidative stress and inflammation associated with diet-induced obesity in mice
}

Florence M. Sohet, Audrey M. Neyrinck, Barbara D. Pachikian, Fabienne C. de Backer, Laure B. Bindels, Petra Niklowitz, Thomas Menke, Patrice D. Cani, Nathalie M. Delzenne

\section{To cite this version:}

Florence M. Sohet, Audrey M. Neyrinck, Barbara D. Pachikian, Fabienne C. de Backer, Laure B. Bindels, et al.. Coenzyme Q10 supplementation lowers hepatic oxidative stress and inflammation associated with diet-induced obesity in mice. Biochemical Pharmacology, 2009, 78 (11), pp.1391. 10.1016/j.bcp.2009.07.008 . hal-00524465

\section{HAL Id: hal-00524465 \\ https://hal.science/hal-00524465}

Submitted on 8 Oct 2010

HAL is a multi-disciplinary open access archive for the deposit and dissemination of scientific research documents, whether they are published or not. The documents may come from teaching and research institutions in France or abroad, or from public or private research centers.
L'archive ouverte pluridisciplinaire HAL, est destinée au dépôt et à la diffusion de documents scientifiques de niveau recherche, publiés ou non, émanant des établissements d'enseignement et de recherche français ou étrangers, des laboratoires publics ou privés. 


\section{Accepted Manuscript}

Title: Coenzyme Q10 supplementation lowers hepatic oxidative stress and inflammation associated with diet-induced obesity in mice

Authors: Florence M. Sohet, Audrey M. Neyrinck, Barbara D. Pachikian, Fabienne C. de Backer, Laure B. Bindels, Petra

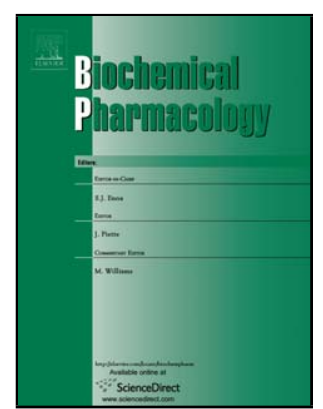

Niklowitz, Thomas Menke, Patrice D. Cani, Nathalie M.

Delzenne

PII:

S0006-2952(09)00638-8

DOI: doi:10.1016/j.bcp.2009.07.008

Reference:

BCP 10264

To appear in: $\quad B C P$

Received date: $\quad$ 12-6-2009

Revised date: $\quad$ 15-7-2009

Accepted date: $\quad$ 15-7-2009

Please cite this article as: Sohet FM, Neyrinck AM, Pachikian BD, de Backer FC, Bindels LB, Niklowitz P, Menke T, Cani PD, Delzenne NM, Coenzyme Q10 supplementation lowers hepatic oxidative stress and inflammation associated with diet-induced obesity in mice, Biochemical Pharmacology (2008), doi:10.1016/j.bcp.2009.07.008

This is a PDF file of an unedited manuscript that has been accepted for publication. As a service to our customers we are providing this early version of the manuscript. The manuscript will undergo copyediting, typesetting, and review of the resulting proof before it is published in its final form. Please note that during the production process errors may be discovered which could affect the content, and all legal disclaimers that apply to the journal pertain. 


\section{Coenzyme Q10 supplementation lowers hepatic oxidative stress and inflammation associated with diet-induced obesity in mice}

Florence M. SOHET ${ }^{\mathrm{a}}$, Audrey M. NEYRINCK ${ }^{\mathrm{a}}$, Barbara D. PACHIKIAN ${ }^{\mathrm{a}}$, Fabienne C. DE BACKER ${ }^{\mathrm{a}}$, Laure B. BINDELS ${ }^{\mathrm{a}}$, Petra NIKLOWITZ ${ }^{\mathrm{b}}$, Thomas MENKE ${ }^{\mathrm{b}}$, Patrice D. CANI $^{\mathrm{a}}$ and Nathalie M. DELZENNE ${ }^{\mathrm{a}}$

${ }^{a}$ Louvain Drug Research Institute, Nutrition and metabolism research group, Université catholique de Louvain, Brussels, Belgium

${ }^{\mathrm{b}}$ Children's Hospital of Datteln, University of Witten/Herdecke, Datteln, Germany

E-mail address of each author: Florence M. SOHET : $\underline{\text { florence.sohet@uclouvain.be; }}$

Audrey M. NEYRINCK: audrey.neyrinck@uclouvain.be; Barbara D.PACHIKIAN: barbara.pachikian@uclouvain.be; Fabienne C. DE BACKER:

fabienne.debacker@uclouvain.be; Laure B. BINDELS: 1aure.bindels@uclouvain.be;

Petra NIKLOWITZ: pf-niklowitz@,web.de; Thomas MENKE :

t.menke@kinderklinikdatteln.de ; Patrice D. CANI : patrice.cani@uclouvain.be; Nathalie M. DELZENNE : nathalie.delzenne@uclouvain.be

Corresponding author: Nathalie M. Delzenne

Louvain Drug Research Institute,

Nutrition and metabolism research group, Université catholique de Louvain,

Unit PMNT, Av. E. Mounier, 73/69, 1200 Brussels, Belgium

Fax: +32027647359 Tel: +32027647367 
email: nathalie.delzenne@uclouvain.be

Running title: High-fat, fructose and coenzyme Q10 in obesity

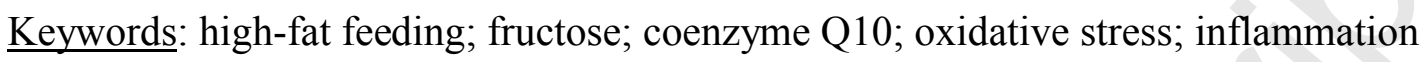
Classification: Metabolic Disorders and Endocrinology 


\section{Abstract}

Background: Diabetes and obesity are metabolic disorders induced by an excessive dietary intake of fat, usually related to inflammation and oxidative stress.

Aims: The aim of the study is to investigate the effect of the antioxidant coenzyme Q10 (CoQ10) on hepatic metabolic and inflammatory disorders associated with diet-induced obesity and glucose intolerance.

Methods: C57bl6/j mice were fed for 8 weeks, either a control diet (CT) or a high fat diet plus $21 \%$ fructose in the drinking water (HFF). CoQ10 supplementation was performed in this later condition (HFFQ).

Results HFF mice exhibit increased energy consumption, fat mass development, fasting glycemia and insulinemia and impaired glucose tolerance. HFF treatment promoted the expression of genes involved in reactive oxygen species production (NADPH oxidase), inflammation (CRP, STAMP-2) and metabolism (CPT1 $\alpha)$ in the liver. CoQ10 supplementation decreased the global hepatic mRNA expression of inflammatory and metabolic stresses markers without changing obesity and tissue lipid peroxides compared to HFF mice. HFF diets paradoxically decreased TBARS (reflecting lipid peroxides) levels in liver, muscle and adipose tissue versus CT group, an effect related to vitamin E content of the diet.

Conclusion: In conclusion, HFF model promotes glucose intolerance and obesity by a mechanism independent on the level of tissue peroxides. CoQ10 tends to decrease hepatic stress gene expression, independently of any modulation of lipid peroxidation, which is classically considered as its most relevant effect. 


\section{Introduction}

The incidence of obesity and type 2 diabetes is increasing all over the world. Oxidative and inflammatory stresses are both considered as important events that participate to the development of metabolic disorders associated with insulin resistance and obesity [1-6]. It has been shown that a high fat (HF) diet promotes endotoxemia and thereby increases proinflammatory cytokines production, namely in the liver [7,8]. Upon obesity, proinflammatory cytokines and oxidative stress have been shown to drive metabolic disturbances, such as insulin resistance and activation of immune system in the liver, in the adipose tissue and in the muscle $[5,6,9]$. Under different pathological states such as diabetes, obesity and hypertriglyceridemia, many tissues are subject to increased reactive oxygen species level, mostly produced through the NADPH oxidase pathway. In the liver, NADPH oxidases enzymes may be involved in several mechanisms leading to insulin resistance and inflammation such as of the activation of c-jun N-terminal kinase, JNK, pathway and interaction with tumour necrosis factor- $\alpha(\mathrm{TNF} \alpha)[10]$.

Among carbohydrates, fructose has been described as a nutrient able to promote insulin resistance and oxidative stress [11]. Those metabolic disturbances have been associated with i.e. hypertriglyceridemia and steatosis, linked to an increased de novo lipogenesis $[12,13]$, modification of the activity of enzymes involved in hepatic glucose metabolism and glucose uptake pathways $[14,15]$ and activation of NADPH oxidase pathway [11]. Coenzyme Q10 (CoQ10) appears as an interesting component, susceptible to counteract several metabolic disturbances associated with obesity. When injected in animals, CoQ10 modulates blood lipid profiles and decreases adipose tissue mRNA expression of the proinflammatory cytokine $\mathrm{TNF} \alpha$ in $o b / o b$ mice, blunts the rosiglitazone increased fat mass in 
$o b / o b$ and diet-induced obesity mice and enhances the rosiglitazone effect on glucose tolerance of $o b / o b$ mice [16]. It is known for a long time as a potent antioxidant, acting either as a primary scavenger of free radicals or in the regeneration of tocopherol. CoQ10 is also involved in oxidative phosphorylation as an electron transporter and is therefore involved in energy homeostasis [17-20]. Data obtained in vitro even suggest its antiinflammatory potency [21-25]. However, the effect of CoQ10 given orally remains only poorly explored in the context of obesity and diabetes. Among the tissues targeted through oral administration of CoQ10, the liver could be the most relevant since this tissue collects it with quite efficacy, and is thus considered as one of the storage pool of CoQ10 [26,27].

Therefore, we have tested the metabolic effect of CoQ10 supplementation in metabolic alterations induced by combination of HF diet and fructose supplementation in mice, with special highlight on liver consequences.

\section{Experimental methods}

\subsection{Animals and diets}

Ten-week-old male C57BL/6J mice (Charles River Laboratories, France) were housed in groups of four mice per cage (eight mice per group) at $22^{\circ} \mathrm{C}$ with sequential light/dark cycle (lights off $6 \mathrm{pm}$, lights on $6 \mathrm{am}$ ) and were given free access to diet and water. They were fed either the control diet (CT group; AO4, SAFE, Villemoison-sur-Orge, France), or a HF diet (SAFE, Villemoison-sur-Orge, France) and given water containing 21\% (wt/V) of fructose (Sigma, St Louis, MO, USA- HFF group) or a HF diet supplemented with $1 \%$ CoQ10 (Kaneka, Japan) and 21\% of fructose in the water (HFFQ group) for 60 days. The $\mathrm{CT}$ diet contained the following $(\mathrm{g} / 100 \mathrm{~g}$ dry diet): protein 19.3, total 
carbohydrate 70.4 (including starch 38, saccharose 3, cellulose 5 and non-digestible carbohydrates 8), lipid 3, vitamin 1.3 and mineral mixture 6 . The HF diet contained $72 \%$ lipids (corn oil and lard), $28 \%$ protein, and $<1 \%$ carbohydrates as energy content. Food intake, taking into account spillage, was recorded weekly for two months. Water consumption was also recorded weekly to analyse fructose intake. The mean value for the weekly assessment of food, water and energy intake was calculated. All mice experiments were approved by the local committee and the housing conditions were as specified by the Belgian Law of November 14, 1993 on the protection of laboratory animals (agreement $\mathrm{n}^{\circ}$ LA 1230314) in accordance with the declaration of Helsinki.

\subsection{Oral glucose tolerance test}

An oral glucose tolerance test was performed 7 weeks after the beginning of the feeding period $[7,28,29]$. Six-hour-fasted mice received an oral load of glucose (Fluka, Buchs, Switzerland) of $3 \mathrm{~g} / \mathrm{kg}$ body wt with a $660 \mathrm{~g} / \mathrm{l}$ glucose solution. Different parameters related to glucose homeostasis have been measured. Blood glucose was determined with a glucose meter (Roche Diagnostics Belgium, Vilvoorde, Belgium) on $3.5 \mu 1$ of blood was collected from the tip of the tail vein, 30 min before and $0,15,30,60,90$ and $120 \mathrm{~min}$ following oral glucose administration. Plasma insulin was measured on $5 \mu 1$ of plasma collected from tail blood at 0 and 15 min using an ELISA kit (Mercodia, Upssala, Sweden). The insulin-resistance index was obtained by multiplication of the area under the curve of glucose between 0 and 15 min after glucose administration and the area under the curve of insulin between 0 and 15 min after glucose administration; its unit is $\mathrm{mM}^{*} \mathrm{pM}^{*} \min ^{2}-[8,30-32]$. The area under the curve was calculated from basal glycemia 
up to 120 minutes after the glucose administration, with no correction of the area by the basal value.

\subsection{Blood samples}

At the end of the experiments, 6-hour-fasted mice were anaesthetized by intra-peritoneal injection of ketamine/xylazine (Anesketin, Eurovet, Bladel, the Netherlands; Rompun, Bayer Belgium, Sint-Truiden, Belgium) 100 and $10 \mathrm{mg} / \mathrm{kg}$, respectively. Cava vein blood samples were collected in EDTA tubes, and plasma was stored at $-80^{\circ} \mathrm{C}$. Cytokines (Tumor necrosis factor $\alpha$, TNF $\alpha$ ) were determined in $25 \mu$ of plasma using a Multiplex kit (Bio-Rad, Nazareth, Belgium) and measured by using Luminex technology (Bio-Plex System $^{\mathrm{TM}}$, Bio-Rad) according to the manufacturer's instructions.

\subsection{Tissue samples}

Fat pads (visceral, epididymal and subcutaneous), heart and vastus lateralis muscle were removed, immersed in liquid nitrogen and stored at $-80^{\circ} \mathrm{C}$ for further mRNA and/or lipids analysis. Liver was excised: most of it was immediately clamped in liquid $\mathrm{N}_{2}$ and kept at $-80^{\circ} \mathrm{C}$ for lipids and mRNA analysis; only a fraction of the main liver lobe was fixedfrozen in isopentane (Lab-Scan, Dublin, Ireland) and kept at $-80^{\circ} \mathrm{C}$ for histological analysis. Liver and fat tissues were weighed.

\subsection{Histological analysis}


For the detection of inflammation and the determination of integrity of tissue, frozen sections were sliced and stained with hematoxylin-eosin, HE. Other sections were stained with diaminobenzidine, DAB (Sigma), in order to detect endogenous peroxidase.

\subsection{Tissues analyses}

Triglycerides (TG), phospholipids (PL) and cholesterol (CHO) were measured in the liver tissue after an extraction with chloroform-methanol (Lab-Scan) according to Folch et al [33]. Tissue lysate was prepared in phosphate buffer by using Ultra-Turrax (IKA, T10 basic, Boutersem, Belgique), until complete tissue lysis. Lipids were extracted by mixing $125 \mu 1$ lysates with $1 \mathrm{ml}$ of chloroform: methanol (2:1). Chloroform phase was evaporated under nitrogen flux, and the dried residue was solubilized in $100 \mu 1$ of isopropanol (Lab-Scan). Liver PL (Wako, Brussels, Belgium), TG and CHO (Elitech diagnostics, Brussels, Belgium) concentrations were measured using kits coupling enzymatic reaction and spectrophotometric detection of reaction end-products

Lipid peroxidation was evaluated by measuring thiobarbituric acid reactive substances, TBARS. Tissue lysate was prepared in saline by using Ultra-Turrax (IKA, T10 basic, Boutersem, Belgique), until complete tissue lysis. Aldehydes contained in tissue lysate reacted with thiobarbiuric acid (Fluka) forming an aldehyde-thiobarbituric acid complex, which can be spectrophotometrically detected [34].

Protein carbonyls were measured spectrophotometrically using 2,4dinitrophenylhydrazine (Aldrich, St Louis, MO, USA), which has an absorbance maxima at $370 \mathrm{~nm}$ and a molar extinction coefficient of $22000 \mathrm{M}^{-1} \mathrm{~cm}^{-1}$ [35]. Briefly, liver 
homogenate was first centrifuged to remove nucleus and cellular debris, and then incubated with streptomycin sulfate (Sigma) to remove nucleic acid in excess. It was then derivatized with 2,4-dinitrophenylhydrazine and proteins were precipitated with trichloroacetic acid (20\% followed by 10\%; Riedel-de Haën, Seelze, Germany). Pellet was finally washed several times before being suspended in guanidine $\mathrm{HCl}$ (Sigma). The carbonyl content in each sample was finally measured spectrophotometrically at $360 \mathrm{~nm}$. To relate carbonyl content to the amount of extracted protein in each sample, the protein content was subsequently measured using Bradford's method (Bio-Rad) [36].

Phosphorylated form of insulin receptor was quantified in liver extracts using Luminex technology. Liver tissue were homogenized in lysis buffer (50mM Tris, $1 \%$ NP40, $5 \mathrm{mM}$ EDTA, $250 \mathrm{mM} \mathrm{NaCl}, 50 \mathrm{mM} \mathrm{NaF}, 1 \mathrm{mM} \mathrm{Na}_{3} \mathrm{VO}_{4}$, proteases inhibitors cocktail (Roche Diagnostics Belgium, Vilvoorde). After 15 min on ice and centrifugation (13 $000 \mathrm{~g}, 10$ $\min , 4^{\circ} \mathrm{C}$ ), supernatants were snap frozen and aliquots were stored at $-80^{\circ} \mathrm{C}$. Protein content of supernatants was determined using the Bradford method [36]. The assay was performed by using a Multiplex kit (Akt pathway phospho7plex, BioSource, Nivelles, Belgium) through Luminex technology (Bio-Plex, Bio-Rad) according to the manufacturer's instructions.

The CoQ9 and CoQ10 concentrations in liver homogenates were measured using HPLC with electrochemical detection and internal standardization modified according to a previously published method for CoQ10 analysis in blood cells [37]. As an internal standard 87 pmol of diethoxy-ubiquinone-10 (kindly provided by B. Janetzky, Technical 
University of Dresden, Germany) in $50 \mu 1$ ethanol were added to a sample of $1 \mathrm{mg}$ tissue homogenate in $100 \mu 1$ saline. The cells were disintegrated by adding cold methanol, extracted with hexane (Riedel-de Haën), and evaporated under a stream of argon. The dry residue was re-dissolved in $50 \mu 1$ ethanol (Merck, Darmstadt, Germany) and injected into the HPLC system.

\subsection{Real-time quantitative PCR}

Total RNA was isolated from subcutaneous adipose tissue and liver using TriPure isolation reagent kit (Roche Diagnostics Belgium, Vilvoorde). cDNA was prepared by reverse transcription of $1 \mu \mathrm{g}$ total RNA using the Kit Reverse transcription System (Promega, Leiden, The Netherlands). Real-time polymerase chain reactions (PCR) were performed with the StepOnePlus real time PCR system and software (Applied Biosystems, Den Ijssel, The Netherlands) using SYBR-Green (Applied Biosystems) for detection. Ribosomal protein L19 (RPL19) RNA was chosen as housekeeping gene. The targeted mouse genes, detailed in table 1, are the following: fatty acid synthase (FAS), NADPH oxidase, cyclooxygenase-2 (COX2), TNF $\alpha, \mathrm{C}$ reactive protein (CRP), sixtransmembrane protein of prostate 2 (STAMP2), Interleukine-6 (IL6), diacylglycerol Oacyltransferase 2 (DGAT2), carnitine palmitoyltransferase $1 \alpha$ (CPT1 $\alpha)$, RPL19 and CD68. All tissues were run in duplicate in a single 96-well reaction plate and data were analysed according to the $2^{-\Delta \mathrm{CT}}$ method [7]. The identity and purity of the amplified product was checked through analysis of the melting curve carried out at the end of amplification. 
Inflammatory score is the sum of NADPH oxidase, COX2, STAMP2, CRP, IL6 and TNF $\alpha$ hepatic mRNA level.

\subsection{Statistical analysis}

Results are presented as Mean \pm SEM. Statistical significance of difference between groups was assessed by one-way ANOVA followed by post hoc Tukey's multiple comparison tests. Correlations between parameters were assessed by Pearson's correlation (GraphPad Prism Software, San Diego, CA, USA; www.graphpad.com). Data with different superscript letters are significantly different $(P<0.05)$ according to the post hoc ANOVA statistical analysis.

\section{Results}

\subsection{Evolution of body weight and metabolic disturbances}

Mice fed on HF diet and fructose supplementation gained more weight than the control mice, and CoQ10 supplementation did not modify body weight evolution (figure 1B). After 7 weeks of treatment all mice slightly lost weight following the oral glucose tolerance test. Body weight gain (figure 1A) increases significantly upon HF diet and fructose supplementation, with no modification following CoQ10 supplementation. This increase is reflected through the increase in fat mass and in particular visceral and epididymal fat mass (figure $2 \mathrm{~A}, \mathrm{~B}, \mathrm{C}$ ). The energy consumption, calculated upon fructose supplementation in the water and diet energy content during the whole duration 
of the experiment, is largely increased in both HFF and HFFQ groups in comparison to CT group (figure 1B). Energetic efficiency is the ratio between the body weight gain $(\mathrm{g})$ and the energy intake (kcal) of each mouse. In our study, HF diet and fructose supplementation did not change this parameter but CoQ10 supplementation tends to increase energetic efficiency (figure 1C). Table 2 shows that there is no increase in liver weight upon treatments and HFF mice even show a tendency to lessen relative liver weight (\% body weight); this tendency becoming significant in HFFQ mice.

\subsection{Coenzyme Q10 enrichment in the liver tissue}

Mice are known to synthesize both CoQ9 and CoQ10, which differs one from each other by the length of their isoprenoid side chain. Liver CoQ9 and CoQ10 contents of CT mice are different, with $2.56 \mathrm{pmol} / \mathrm{mg}$ of CoQ10 and $70.01 \mathrm{pmol} / \mathrm{mg}$ of CoQ9. Liver CoQ9 content in HFF and HFFQ groups and liver CoQ10 content in HFF group are not modified as compared to controls. However CoQ10 supplementation increases by more than 40 times the liver CoQ10 content in HFFQ versus HFF and CT group (figure 3 A, B).

\subsection{Lipid homeostasis}

The histological analysis of the liver tissue reveals the presence of microvesicular lipid droplets in all groups but macrovesicular lipid droplets accumulate preferentially in HFF and HFFQ groups, signing changes in lipid storage in HF and fructose supplemented 
mice (figure 4). The TG, CHO and PL accumulation in the liver tissue was not significantly modified versus CT diet (table 2). However animals supplemented with CoQ10 show a tendency of increased liver TG. Liver weight (table 2), expressed in g, is significantly increased following HF diet and fructose supplementation while it shows a tendency to decrease when expressed in $\%$ of body weight, signing that the extent of changes in total body weight largely exceeded the modification in liver weight upon treatment. The addition of CoQ10 lessens the increase in liver weight (expressed in $\mathrm{g}$ ) and significantly decreases the relative liver weight (expressed in $\%$ of body weight). Serum TG, non-esterified fatty acid, and alanine amino transferase and aspartate amino transferase activities were not modified by dietary treatment (data not shown). The expression of the genes involved in lipogenesis (FAS), in fatty acid esterification (DGAT2) and in transport of long chain fatty acids across the mitochondrial membrane, where they can be oxidized (CPT1 $\alpha)$ was assessed by the measurement of mRNA content. HFF treatment increases mRNA level of DGAT2 and CPT1 $\alpha$, with no effect on FAS mRNA (table2). However, the addition of CoQ10 blunted the HFF effect on CPT1 $\alpha$.

\subsection{Glucose homeostasis}

HFF treatment induced glucose intolerance and insulin resistance, as shown by the higher area under the curve and insulin resistance index (figure $5 \mathrm{C}, \mathrm{D}, \mathrm{E}$ ). In both $\mathrm{HFF}$ and HFFQ groups, fasting glycemia showed a tendency to increase (figure 4 B) and fasting insulinemia a significant increase as compared to controls (figure $5 \mathrm{~A}$ ). This latter effect was even higher in CoQ10 treated animals. Insulin receptor phosphorylation on tyrosines 
sites 1162 and 1163 is the limiting step of the activation of the insulin receptor. Similar insulin receptor phosphorylation level, as seen between the three groups, signs no difference in the activation rate of insulin receptor (Figure 5 F). However, as HFF and HFFQ fed mice show a higher fasting insulinemia compared to CT mice (figure $5 \mathrm{~A}$ ), it might reflect a lower response to insulin in HFF and HFFQ fed mice.

\subsection{Assessment of hepatic markers of oxidative and inflammatory stresses}

HFF treatment significantly increases NADPH oxidase mRNA content in the liver tissue as compared to CT group, while CoQ10 reduces this alteration (figure $6 \mathrm{~A}$ ). The histological analysis of peroxidase positive cells - signing the total immune cells- in the liver tissue reveals an increase in their number in both HFF and HFFQ groups. No significant modification of CD68 mRNA, reflecting the presence of monocytes and macrophages, occurred in the treated groups (figure $6 \mathrm{G}$ ). HFF treatment increases by several fold the inflammatory protein precursors, STAMP2 and CRP, respectively by 6 and 3 fold (figure $6 \mathrm{C}$, D). COX2, IL6 and TNF $\alpha$ mRNA show no significant modification upon treatment but a similar profile: an increase by HFF and a decrease in HFFQ (figure 6 B, E, F). An inflammatory score was calculated, by summing the mRNA level of all COX2, STAMP2, CRP, IL6 and TNF $\alpha$ hepatic mRNA level. This inflammatory score is significantly increased upon HFF treatment and tend to be blunted upon CoQ10 supplementation (Figure 6 I). Serum TNF $\alpha$ evolution upon treatment is similar to the evolution of TNF $\alpha$ mRNA in the liver tissue upon same treatments (figure $6 \mathrm{~F}, \mathrm{H})$. TBARS have been measured in the liver, muscle, adipose tissues and in the 
heart (table 3 A): HFF treatment leads to a decrease in peroxidation end products in all tissues, except in the subcutaneous adipose tissue; this drop being significant in liver and visceral white adipose tissue. CoQ10 per se did not modify lipid peroxides level versus the HFF group. Liver carbonylated proteins were modified neither by HFF treatment nor upon CoQ10 supplementation (table 3 B). A clear correlation (figure 7) could be done between markers of inflammatory stress - CRP or STAMP2 mRNA expression- and oxidative stress - NADPH oxidase mRNA expression- (figure 7 B,C,E) suggesting an association between inflammation and oxidative stress in a model of diet induced obesity. Moreover, correlations between the markers inflammation or oxidative stress (CRP, STAMP2 and NADPH oxidase mRNA expression) and CPT1 $\alpha$ mRNA expression could also be done (figure 7 A,D,F).

\section{Discussion}

The aim of the study was to assess the effect of CoQ10 oral administration on the metabolic disturbances occurring in a model of obesity in mice, by focusing on potential effect that occur independently on the well known protective effect of CoQ10 against lipid peroxidation.

The first part of the discussion will focus on the model used in our study. We know that HF feeding is responsible for the development of obesity and leads to insulin resistance within a few weeks in mice [8]. Here we confirm that the HF diet-induced obesity and glucose intolerance are independent of lipid peroxidation, since the level of tissue lipid peroxides are paradoxically strongly blunted due to a high vitamin E content of the HF 
diet [32]. On the other hand, fructose supplementation has been extensively studied in rodents, especially in rats, and has been shown to promote insulin resistance and inflammation $[14,15]$. Few mice studies suggest that the metabolic response towards high fructose diets provides discrepant results concerning the effect on body weight, glucose and lipid homeostasis [38-40]. Messier et al [39] have shown that the combination of HF diet and fructose supplementation in mice leads to increased weight gain and impairments in blood glucose regulation, but this combination model has not been extensively studied. In our study, we confirm the huge accumulation of fat mass and the increase in body weight when high fat is supplemented with fructose.

Concerning the liver, we have observed that HF plus fructose supplementation in mice changes several, but not all the enzymes involved in fatty acid storage. We did not found any inducement of the expression of key enzymes involved in lipogenesis since HFF treatment did not increased FAS. However, the observed increase in the expression of DGAT2 - an enzyme which catalyses the final step of TG synthesis- could also be implicated in hepatic lipid accumulation, together with the fact that fructose is an excellent lipogenic substrate $[12,41]$. HF plus fructose diet induces a shift from microvesicular towards macrovesicular lipid storage as analysed by histology. However, the content in TG, CHO and PL was only slightly and not significantly increased. Therefore, it seems that steatosis in this nutritional context is more related to qualitative changes of lipid droplet than to drastic changes in lipid storage. The lack of massive lipid accumulation might be explained by the fact that the sampling was performed at a late post-absorptive state (six hours after food removal). Moreover, the increase in mRNA 
expression of CPT $1 \alpha$ could drive an increased oxidation of fatty acids, thus counteracting a huge increase in lipid accumulation despite the high content of fat in the diet. HFF mice also present an altered glucose response, already generated through HF diet given independently on fructose administration [8]. Interestingly, this HFF models also drives inflammation in the liver tissue as shown by the higher COX2, CRP, IL6, TNF $\alpha$ and STAMP2 mRNA levels. HFF treatment also provokes an increased expression of NADPH oxidase, considered as an early event associating oxidative reactive species production and inflammatory stress $[10,42]$. Despite this fact and as previously demonstrated, liver lipid peroxide content remains very low in the liver tissue[32].

Several data recently obtained in human have tried to correlate the markers of lipid peroxidation with metabolic alterations linked to obesity. The oxidative stress, assessed i.e. by lipid peroxides measurement in the blood, is increased in patients exhibiting a metabolic syndrome [43]. By analysing several markers of oxidative stress, Rytter et al have shown that only 8 -iso-PGF $2 \alpha$ is positively correlated with HbA1c and blood glucose in diabetic subjects [44]. Our data in animal clearly show that lipid peroxidation is not a prerequisite to observe the metabolic alterations linked to high fat diet induced obesity.

Curiously, hepatic CPT1 $\alpha$ mRNA increases upon HFF treatment. Besides its role in the transport of long chain fatty acids across the mitochondrial membranes, CPT1 $\alpha$ activity has recently been associated with food intake in rats. In the brain, an inhibition of CPT1 $1 \alpha$ activity could lead to the accumulation of fatty acids and this accumulation can be integrated as a signal of nutrient abundance finally leading to a decreased food intake 
[45]. Furthermore, liver CPT1 $\alpha$ expression has been shown to be increased following HF diet [46], exercise training or diet restriction [47]. Therefore, we hypothesised that CPT1 $\alpha$ could be seen as a marker of global catabolic state under metabolic stress condition. In our study, a clear correlation (figure 7) could be found between markers of inflammatory stress and oxidative stress suggesting that all these metabolic features are clearly present and linked one to each other in this model of dietary induced obesity.

We have used the model HF diet supplemented with fructose to assess the potential interest of CoQ10 supplementation. CoQ10 is an important cofactor of the electron transport chain in mitochondrial respiration, being involved in energy homeostasis $[17,19,48,49]$. Furthermore it is also a cofactor of mitochondrial uncoupling proteins, which activation leads to a reduction of mitochondrial-free radical generation [50,51]. In our study, beside a described low tissue uptake [26,27], we found a 40 times increase of CoQ10 level in the liver tissue.

However, in our study, we did not find any modification of liver lipid accumulation following CoQ10 supplementation. Another antioxidant such as vitamin E, has been shown to lessen the hepatic fibrosis occurring in a model of mice mimicking the steatohepatitis (methionine and choline deficient diet) [52] We can therefore propose that the beneficial effect of antioxidant might be dependent on the nature of the hepatic alteration occurring upon nutritional manipulation, and would be more efficient to counteract the pathogenic process leading to steatohepatitis than counteracting steatosis per se.

Some studies suggest that CoQ10 may exhibit anti-inflammatory properties, but most of those data have been obtained in vitro. Doring et al.[23] and Schmelzer et al. [24] 
analysed in silico the CoQ10 effect on in vitro human and murine macrophages and found upregulation of 17 genes functionally connected by signalling pathways of Gprotein coupled receptors, JAK/STAT, integrin and $\beta$-arrestin, and five of this genes code for protein involved in inflammation (IL5, thrombin, vitronectin, vitronectin receptor and CRP). In vitro macrophages cells lines (RAW and THP-1) pretreated with CoQ10 show reduced TNF $\alpha$ release (RAW)[22] and reduced TNF $\alpha$, MIP-1 $\alpha$ and RANTES (THP1)[25] after LPS stimulation. Finally, Fuller et al. observed that CoQ10 is able to suppress UV radiation or IL-1-induced inflammatory response in dermal fibroblasts. Here we provide for the first time in vivo evidence that an accumulation of CoQ10 in the liver tissue, allows to blunt NADPH oxidase expression and inflammatory stress, independently on any effect on lipid peroxidation, in a model of diet induced obesity. This is rather interesting, since it is in accordance with the data obtained in vivo in other models, and that focused on systemic inflammation. However, CoQ10 supplementation does not blunt the increase of total tissue fixed or recruited immune cells following HFF treatment as assessed by histological analysis of peroxidase positive cells. Another in vivo study shows that in a model of hypertensive rats developing metabolic syndrome following HF diet, CoQ10 reduce serum CRP level, thereby decreasing the inflammatory stress [53]. In another study, anti-inflammatory properties of CoQ10 on serum CRP levels of baboons have also been observed, but only when combined with vitamin E. This modification of serum CRP level was associated with an increase blood total antioxidant status [54]. Recently, Carmona et al. [16] showed that i.p. injection of CoQ10 modulates blood lipid profiles and the expression of pro-inflammatory cytokine in the adipose tissue. Those different in vitro and in vivo studies seems to show a potential role of 
CoQ10 in inflammation, but its potential anti-inflammatory effect is still not clearly associated with any improvements of metabolic disorders. While others antioxidants have clearly been associated with improvements of metabolic disorders e.g. berries rich in anthocyanin induce a decrease in adipose tissue inflammation which is associated with a reduction of insulin resistance[55].

We propose, in view of our study, that CoQ10, when given orally, is able to target the liver tissue, and to lessen inflammatory stress associated with obesity in mice in this tissue, independent on any action on lipid peroxidation. However, this effect was not sufficient to counteract fat mass development and other metabolic alterations occurring upon obesity (steatosis, altered glucose response). The hepatic effect of CoQ10 could be interesting to study in the context of non alcoholic steatohepatitis that clearly associate fat accumulation and inflammation in the liver tissue.

Conflict of interest statement

The authors have no conflict of interest.

\section{Acknowledgments}

This work was supported by Kaneka Inc. and by the Région Wallonne (WalNut 20

Project). P.D. Cani is a Research Associate from the FNRS Belgium.

Reference list 
[1] Evans JL, Goldfine ID, Maddux BA, and Grodsky GM. Oxidative stress and stress-activated signaling pathways: a unifying hypothesis of type 2 diabetes. Endocr Rev 2002;23:599-622.

[2] Maritim AC, Sanders RA, and Watkins JB, III. Diabetes, oxidative stress, and antioxidants: a review. J Biochem Mol Toxicol 2003;17:24-38.

[3] Wellen KE and Hotamisligil GS. Inflammation, stress, and diabetes. J Clin Invest 2005;115:1111-9.

[4] Fridlyand LE and Philipson LH. Reactive species, cellular repair and risk factors in the onset of type 2 diabetes mellitus: review and hypothesis. Curr Diabetes Rev 2006;2:241-59.

[5] Milagro FI, Campion J, and Martinez JA. Weight gain induced by high-fat feeding involves increased liver oxidative stress. Obesity (Silver Spring) 2006;14:1118-23.

[6] Shoelson SE, Herrero L, and Naaz A. Obesity, inflammation, and insulin resistance. Gastroenterology 2007;132:2169-80.

[7] Cani PD, Amar J, Iglesias MA, Poggi M, Knauf C, Bastelica D, et al. Metabolic endotoxemia initiates obesity and insulin resistance. Diabetes 2007;56:1761-72.

[8] Cani PD, Bibiloni R, Knauf C, Waget A, Neyrinck AM, Delzenne NM, et al. Changes in gut microbiota control metabolic endotoxemia-induced inflammation in high-fat diet-induced obesity and diabetes in mice. Diabetes 2008;57:1470-81.

[9] Anderson EJ, Lustig ME, Boyle KE, Woodlief TL, Kane DA, Lin CT, et al. Mitochondrial $\mathrm{H} 2 \mathrm{O} 2$ emission and cellular redox state link excess fat intake to insulin resistance in both rodents and humans. J Clin Invest 2009.

[10] Guichard C, Moreau R, Pessayre D, Epperson TK, and Krause KH. NOX family NADPH oxidases in liver and in pancreatic islets: a role in the metabolic syndrome and diabetes? Biochem Soc Trans 2008;36:920-9.

[11] Rayssiguier Y, Gueux E, Nowacki W, Rock E, and Mazur A. High fructose consumption combined with low dietary magnesium intake may increase the incidence of the metabolic syndrome by inducing inflammation. Magnes Res 2006;19:237-43.

[12] Elliott SS, Keim NL, Stern JS, Teff K, and Havel PJ. Fructose, weight gain, and the insulin resistance syndrome. Am J Clin Nutr 2002;76:911-22.

[13] Ouyang X, Cirillo P, Sautin Y, McCall S, Bruchette JL, Diehl AM, et al. Fructose consumption as a risk factor for non-alcoholic fatty liver disease. J Hepatol 2008;48:993-9.

[14] Delbosc S, Paizanis E, Magous R, Araiz C, Dimo T, Cristol JP, et al. Involvement of oxidative stress and NADPH oxidase activation in the development of cardiovascular complications in a model of insulin resistance, the fructose-fed rat. Atherosclerosis 2005;179:43-9.

[15] Yadav H, Jain S, and Sinha PR. Antidiabetic effect of probiotic dahi containing Lactobacillus acidophilus and Lactobacillus casei in high fructose fed rats. Nutrition 2007;23:62-8.

[16] Carmona MC, Lefebvre P, Lefebvre B, Galinier A, Benani A, Jeanson Y, et al. Coadministration of coenzyme $\mathrm{Q}$ prevents rosiglitazone-induced adipogenesis in ob/ob mice. Int J Obes (Lond) 2009;33:204-11. 
[17] Crane FL. Biochemical functions of coenzyme Q10. J Am Coll Nutr 2001;20:591-8.

[18] James AM, Smith RA, and Murphy MP. Antioxidant and prooxidant properties of mitochondrial Coenzyme Q. Arch Biochem Biophys 2004;423:47-56.

[19] Crane FL. Discovery of ubiquinone (coenzyme Q) and an overview of function. Mitochondrion 2007;7 Suppl:S2-S7.

[20] Bentinger M, Brismar K, and Dallner G. The antioxidant role of coenzyme Q. Mitochondrion 2007;7 Suppl:S41-S50.

[21] Schmelzer C, Lorenz G, Rimbach G, and Doring F. Influence of Coenzyme Q_ $\{10\}$ on release of pro-inflammatory chemokines in the human monocytic cell line THP-1. Biofactors 2007;31:211-7.

[22] Schmelzer C, Lorenz G, Lindner I, Rimbach G, Niklowitz P, Menke T, et al. Effects of Coenzyme Q10 on TNF-alpha secretion in human and murine monocytic cell lines. Biofactors 2007;31:35-41.

[23] Schmelzer C, Lindner I, Vock C, Fujii K, and Doring F. Functional connections and pathways of coenzyme Q10-inducible genes: an in-silico study. IUBMB Life 2007;59:628-33.

[24] Schmelzer C, Lindner I, Rimbach G, Niklowitz P, Menke T, and Doring F. Functions of coenzyme Q10 in inflammation and gene expression. Biofactors 2008;32:179-83.

[25] Schmelzer C, Lorenz G, Rimbach G, and Doring F. In Vitro Effects of the Reduced Form of Coenzyme Q(10) on Secretion Levels of TNF-alpha and Chemokines in Response to LPS in the Human Monocytic Cell Line THP-1. J Clin Biochem Nutr 2009;44:62-6.

[26] Bhagavan HN and Chopra RK. Coenzyme Q10: absorption, tissue uptake, metabolism and pharmacokinetics. Free Radic Res 2006;40:445-53.

[27] Miles MV. The uptake and distribution of coenzyme Q10. Mitochondrion 2007;7 Suppl:S72-S77.

[28] Cani PD, Knauf C, Iglesias MA, Drucker DJ, Delzenne NM, and Burcelin R. Improvement of glucose tolerance and hepatic insulin sensitivity by oligofructose requires a functional glucagon-like peptide 1 receptor. Diabetes 2006;55:1484-90.

[29] Knauf C, Cani PD, Perrin C, Iglesias MA, Maury JF, Bernard E, et al. Brain glucagon-like peptide-1 increases insulin secretion and muscle insulin resistance to favor hepatic glycogen storage. J Clin Invest 2005;115:3554-63.

[30] Guerre-Millo M, Rouault C, Poulain P, Andre J, Poitout V, Peters JM, et al. PPAR-alpha-null mice are protected from high-fat diet-induced insulin resistance. Diabetes 2001;50:2809-14.

[31] Lin HY, Yu IC, Wang RS, Chen YT, Liu NC, Altuwaijri S, et al. Increased hepatic steatosis and insulin resistance in mice lacking hepatic androgen receptor. Hepatology 2008;47:1924-35.

[32] Sohet FM, Neyrinck AM, Dewulf EM, Bindels LB, Portois L, Malaisse WJ, et al. Lipid peroxidation is not a prerequisite for the development of obesity and diabetes in high-fat-fed mice. Br J Nutr 2009;23:1-8.

[33] FOLCH J, LEES M, and SLOANE STANLEY GH. A simple method for the isolation and purification of total lipides from animal tissues. J Biol Chem 1957;226:497-509. 
[34] Esterbauer H and Cheeseman KH. Determination of aldehydic lipid peroxidation products: malonaldehyde and 4-hydroxynonenal. Methods Enzymol 1990;186:407-21.

[35] Levine RL, Garland D, Oliver CN, Amici A, Climent I, Lenz AG, et al. Determination of carbonyl content in oxidatively modified proteins. Methods Enzymol 1990;186:464-78.

[36] Bradford MM. A rapid and sensitive method for the quantitation of microgram quantities of protein utilizing the principle of protein-dye binding. Anal Biochem 1976;72:248-54.

[37] Niklowitz P, Menke T, Andler W, and Okun JG. Simultaneous analysis of coenzyme Q10 in plasma, erythrocytes and platelets: comparison of the antioxidant level in blood cells and their environment in healthy children and after oral supplementation in adults. Clin Chim Acta 2004;342:219-26.

[38] Ostos MA, Recalde D, Baroukh N, Callejo A, Rouis M, Castro G, et al. Fructose intake increases hyperlipidemia and modifies apolipoprotein expression in apolipoprotein AI-CIII-AIV transgenic mice. J Nutr 2002;132:918-23.

[39] Messier C, Whately K, Liang J, Du L, and Puissant D. The effects of a high-fat, high-fructose, and combination diet on learning, weight, and glucose regulation in C57BL/6 mice. Behav Brain Res 2007;178:139-45.

[40] Barbosa CR, Albuquerque EM, Faria EC, Oliveira HC, and Castilho LN. Opposite lipemic response of Wistar rats and C57BL/6 mice to dietary glucose or fructose supplementation. Braz J Med Biol Res 2007;40:323-31.

[41] Monetti M, Levin MC, Watt MJ, Sajan MP, Marmor S, Hubbard BK, et al. Dissociation of hepatic steatosis and insulin resistance in mice overexpressing DGAT in the liver. Cell Metab 2007;6:69-78.

[42] Gauss KA, Nelson-Overton LK, Siemsen DW, Gao Y, DeLeo FR, and Quinn MT. Role of NF-kappaB in transcriptional regulation of the phagocyte NADPH oxidase by tumor necrosis factor-alpha. J Leukoc Biol 2007;82:729-41.

[43] Grattagliano I, Palmieri VO, Portincasa P, Moschetta A, and Palasciano G. Oxidative stress-induced risk factors associated with the metabolic syndrome: a unifying hypothesis. J Nutr Biochem 2008;19:491-504.

[44] Rytter E, Vessby B, Asgard R, Johansson C, Sjodin A, bramsson-Zetterberg L, et al. Glycaemic status in relation to oxidative stress and inflammation in wellcontrolled type 2 diabetes subjects. Br J Nutr 2009;101:1423-6.

[45] Mera P, Bentebibel A, Lopez-Vinas E, Cordente AG, Gurunathan C, Sebastian D, et al. C75 is converted to C75-CoA in the hypothalamus, where it inhibits carnitine palmitoyltransferase 1 and decreases food intake and body weight. Biochem Pharmacol 2008.

[46] Zou Y, Du H, Yin M, Zhang L, Mao L, Xiao N, et al. Effects of high dietary fat and cholesterol on expression of PPARalpha, LXRalpha, and their responsive genes in the liver of apoE and LDLR double deficient mice. Mol Cell Biochem 2009;323:195-205.

[47] Huang H, Iida KT, Sone H, Yokoo T, Yamada N, and Ajisaka R. The effect of exercise training on adiponectin receptor expression in KKAy obese/diabetic mice. J Endocrinol 2006;189:643-53. 
[48] Ernster L and Dallner G. Biochemical, physiological and medical aspects of ubiquinone function. Biochim Biophys Acta 1995;1271:195-204.

[49] Turunen M, Olsson J, and Dallner G. Metabolism and function of coenzyme Q. Biochim Biophys Acta 2004;1660:171-99.

[50] Beal MF. Mitochondrial dysfunction and oxidative damage in Alzheimer's and Parkinson's diseases and coenzyme Q10 as a potential treatment. J Bioenerg Biomembr 2004;36:381-6.

[51] Chaturvedi RK and Beal MF. Mitochondrial approaches for neuroprotection. Ann N Y Acad Sci 2008;1147:395-412.

[52] Phung N, Pera N, Farrell G, Leclercq I, Hou JY, and George J. Pro-oxidantmediated hepatic fibrosis and effects of antioxidant intervention in murine dietary steatohepatitis. Int J Mol Med 2009;24:171-80.

[53] Kunitomo M, Yamaguchi Y, Kagota S, and Otsubo K. Beneficial effect of coenzyme Q10 on increased oxidative and nitrative stress and inflammation and individual metabolic components developing in a rat model of metabolic syndrome. J Pharmacol Sci 2008;107:128-37.

[54] Wang XL, Rainwater DL, Mahaney MC, and Stocker R. Cosupplementation with vitamin $\mathrm{E}$ and coenzyme Q10 reduces circulating markers of inflammation in baboons. Am J Clin Nutr 2004;80:649-55.

[55] Defuria J, Bennett G, Strissel KJ, Perfield JW, Milbury PE, Greenberg AS, et al. Dietary Blueberry Attenuates Whole-Body Insulin Resistance in High Fat-Fed Mice by Reducing Adipocyte Death and Its Inflammatory Sequelae. J Nutr 2009. 


\section{Figures}

Figure 1: Body weight gain and consumption. Body weight gain in CT, HFF and HFFQ mice after an 8-week period of feeding (A). Evolution of body weight during the 8-week period of feeding (B). Energy consumption per cage of four mice, calculated upon fructose supplementation and diet energy content, during the 8 -week period of feeding (C). Energetic efficiency in CT, HFF and HFFQ mice, calculated upon body weight gain

and energy consumption (D). Data are mean \pm SEM. Data with different superscript letters are significantly different $\mathrm{p}<0.05$, according to the post hoc ANOVA statistical analysis (A,B,D). Data are mean of 2 cages with 4 mice each $(n=2, B)$. CT $(n=7)$ Control diet, HFF ( $n=8)$ High-fat diet and fructose, HFFQ $(n=8)$ High-fat diet, fructose and coenzyme Q10

Figure 2: Effect of different diet on adipose tissue weight: visceral (A), epididymal (B) and subcutaneous (C) in CT $(n=7)$, HFF $(n=8)$ and HFFQ $(n=8)$ mice after an 8-week period of feeding. Data are mean \pm SEM. Data with different superscript letters are significantly different $\mathrm{p}<0.05$, according to the post hoc ANOVA statistical analysis. CT Control diet, HFF High-fat diet and fructose, HFFQ High-fat diet, fructose and coenzyme Q10

Figure 3: Effect of different diet on CoQ content in the liver: CoQ10 (A) and CoQ9 (B) in CT $(n=7)$, HFF $(n=8)$ and HFFQ $(n=8)$ mice after an 8-week period of feeding. Data are mean \pm SEM. Data with different superscript letters are significantly different $p<0.05$, 
according to the post hoc ANOVA statistical analysis. CoQ coenzyme Q, CT Control diet, HFF High-fat diet and fructose, HFFQ High-fat diet, fructose and coenzyme Q10

Figure 4: Histological analysis of liver tissue (HE staining) in CT (A), HFF (B) and HFFQ (C) mice. Bar $=50 \mu \mathrm{m}$. CT Control diet, HFF High-fat diet and fructose, HFFQ High-fat diet, fructose and coenzyme Q10

Figure 5: Effect of different diet on glucose tolerance in mice A. Fasted plasma insulin (pmo/l) in CT $(n=7)$, HFF $(n=8)$ and HFFQ $(n=8)$ mice after a 7 -week period of feeding. B. Fasted plasma glucose $(\mathrm{mmol} / \mathrm{l})$ in the same groups; $\mathrm{p}=0.05$ C. Plasma glucose following an oral glucose load (3 $\mathrm{g} / \mathrm{kg})$ in CT (closed squares), HFF (closed circles) and HFFQ (open squares). D. Area under the curve of glycemia (AUC, mmol/1*min) in the same groups. E The insulin-resistance index -AUC glucose 0-15 min X AUC insulin 0$15 \mathrm{~min}$ - in the same groups $[\mu \mathrm{mol} * 15 \mathrm{~min}]^{2} . \mathbf{F}$. The phosphorylation of insulin receptor in the same groups. Data are mean \pm SEM. Data with different superscript letters are significantly different $\mathrm{p}<0.05$, according to the post hoc ANOVA statistical analysis. AUC, area under the curve, IR insulin receptor, CT Control diet, HFF High-fat diet and fructose, HFFQ High-fat diet, fructose and coenzyme Q10

Figure 6: Effect of different diet on inflammatory and oxidative stress markers in CT $(\mathrm{n}=7)$, HFF $(\mathrm{n}=8)$ and HFFQ $(\mathrm{n}=8)$ mice after an 8 -week period of feeding A. Liver NADPH oxidase mRNA level (relative expression). B. Liver COX2 mRNA level 
(relative expression). C. Liver STAMP2 mRNA level (relative expression). D. Liver CRP mRNA level (relative expression). E. Liver IL6 mRNA level (relative expression). F. Liver TNF $\alpha$ mRNA level (relative expression). G. Liver CD68 mRNA level (relative expression). H. TNF $\alpha$ level in serum ( $\mathrm{pg} / \mathrm{ml})$. I. Liver inflammatory score, sum of liver NADPH oxidase, COX2, STAMP2, CRP, TNF $\alpha$ and IL6 mRNA level (relative expression). Data are mean \pm SEM. Data with different superscript letters are significantly different $p<0.05$, according to the post hoc ANOVA statistical analysis. TNF- $\alpha$ tumor necrosis factor- $\alpha$, STAMP2 six-transmembrane protein of prostate 2 , COX-2 cyclooxygenase-2, IL6 interleukine 6, CRP C reactive protein, CT Control diet, HFF High-fat diet and fructose, HFFQ High-fat diet, fructose and coenzyme Q10

Figure 7: Correlations between liver CRP, STAMP2, CPT1 $\alpha$ and NADPH oxidase mRNA. Correlation between: A. liver CRP mRNA and liver CPT1 $\alpha$ mRNA, B. liver CRP mRNA and liver STAMP2 mRNA, C. liver CRP mRNA and liver NADPH oxidase mRNA, D. liver STAMP2 mRNA and liver CPT1 $\alpha$ mRNA, E. liver STAMP2 mRNA and liver NADPH oxidase mRNA, F. liver CPT1 $\alpha$ mRNA and liver NADPH oxidase mRNA. $\mathrm{n}=23$, statistical analysis: Pearson's $\mathrm{r}$ correlations. CRP $\mathrm{C}$ reactive protein, STAMP2 six-transmembrane protein of prostate 2, CPT1 $\alpha$ carnitine palmitoyltransferase $1 \alpha$ 


\section{Tables}

Table 1: Primers sequences used for real-time quantitative PCR

TNF- $\alpha$, tumor necrosis factor- $\alpha$; RPL19, ribosomal protein L19; STAMP2, sixtransmembrane protein of prostate 2 ; COX-2, cyclooxygenase-2; FAS, fatty acid synthase; IL6, interleukine-6; DGAT-2, diacylglycerol O-acyltransferase 2 ; CPT1- $\alpha$, carnitine palmitoyltransferase $1 \alpha ; \mathrm{CRP}, \mathrm{C}$ reactive protein.

Table 2: Liver parameters

Data are mean \pm SEM. Data with different superscript letters are significantly different $\mathrm{p}<0.05$, according to the post hoc ANOVA statistical analysis. TG triglycerides, $\mathrm{CHO}$ cholesterol, PL phospholipids, FAS fatty acid synthase, DGAT2 diacylglycerol Oacyltransferase 2, CPT $1 \alpha$ carnitine palmitoyltransferase $1 \alpha, \mathrm{CT}$ Control diet, HFF Highfat diet and fructose, HFFQ High-fat diet, fructose and coenzyme Q10

Table 3: TBARS and carbonylated proteins in tissues.

Data are mean \pm SEM $(n \geq 6)$. Data with different superscript letters are significantly different $\mathrm{p}<0.05$, according to the post hoc ANOVA statistical analysis. CT Control diet, HFF High-fat diet and fructose, HFFQ High-fat diet, fructose and coenzyme Q10, SAT subcutaneous adipose tissue, EAT epididymal adipose tissue, VAT visceral adipose tissue. 
Table 1

\begin{tabular}{lcc}
\hline & \multicolumn{1}{c}{ Forward } & Reverse \\
\hline TNF- $\alpha$ & AAATGGGCTCCCTCTCATCAGTTC & TCTGCTTGGTGGTTTGCTACGAC \\
RPL19 & GAAGGTCAAAGGGAATGTGTTCA & CCTTGTCTGCCTTCAGCTTGT \\
NADPH oxidase & TTGGGTCAGCACTGGCTCTG & TGGCGGTGTGCAGTGCTATC \\
COX-2 & TGACCCCCAAGGCTCAAATAT & TGAACCCAGGTCCTCGCTTA \\
FAS & TTCCAAGACGAAAATGATGC & AATTGTGGGATCAGGAGAGC \\
DGAT2 & ACTCTGGAGGTTGGCACCAT & GGGTGTGGCTCAGGAGGAT \\
IL6 & TCCTACCCCAACTTCCAATGCTC & TTGGATGGTCTTGGTCCTTAGCC \\
CPT1 $\alpha$ & AGACCGTGAGGAACTCAAACCTAT & TGAAGAGTCGCTCCCACT \\
CRP & CCATTTCTACACTGCTCTGAGCAC & CCAAAATATGAGAATGTCGTTAGAGTTC \\
STAMP2 & TCAAATGCGGAATACCTTGCT & GCATCTAGTGTTCCTGACTGGA \\
CD68 & CTTCCCACAGGCAGCACAG & AATGATGAGAGGCAGCAAGAGG \\
\hline
\end{tabular}


Table 2

\begin{tabular}{lccc}
\hline & CT & HFF & HFFQ \\
\hline Liver weight(g) & $1,06 \pm 0,03^{\mathrm{a}}$ & $1,19 \pm 0,03^{\mathrm{b}}$ & $1,14 \pm 0,03^{\mathrm{ab}}$ \\
Liver weight(\% body weight) & $4,0 \pm 0,1^{\mathrm{a}}$ & $3,8 \pm 0,1^{\mathrm{ab}}$ & $3,5 \pm 0,1^{\mathrm{b}}$ \\
Liver TG (nmol/mg prot) & $87,5 \pm 7,9$ & $92,9 \pm 14,4$ & $114,6 \pm 7,7$ \\
Liver CHO(nmol/mg prot) & $64,1 \pm 4,5$ & $72,5 \pm 3,4$ & $75,4 \pm 2,8$ \\
Liver PL(nmol/mg prot) & $87,8 \pm 2,4$ & $91,4 \pm 3,3$ & $89,3 \pm 3,6$ \\
\hline Liver FAS (relative expression) & $1,00 \pm 0,13$ & $0,84 \pm 0,05$ & $0,99 \pm 0,10$ \\
Liver CPT1 $\alpha$ (relative expression) & $1,00 \pm 0,08^{\mathrm{a}}$ & $1,88 \pm 0,38^{\mathrm{b}}$ & $1,28 \pm 0,11^{\mathrm{ab}}$ \\
Liver DGAT2 (relative expression) & $1,00 \pm 0,04^{\mathrm{a}}$ & $1,45 \pm 0,07^{\mathrm{b}}$ & $1,46 \pm 0,10^{\mathrm{b}}$ \\
\hline
\end{tabular}


Table 3

A Liver TBARS

Muscle TBARS

SAT TBARS

EAT TBARS

VAT TBARS

Heart TBARS

( $\mu \mathrm{mol} \mathrm{MDA} / \mathrm{L}$ homogenate $\mathrm{H} / 10$ )

B Liver carbonylated proteins

( nmol/mg prot)

CT $\quad$ HFF HFFQ

$\begin{array}{ccc}13,0 \pm 2,2^{\mathrm{a}} & 4,9 \pm 0,3^{\mathrm{b}} & 5,1 \pm 1,4^{\mathrm{b}} \\ 4,8 \pm 0,8^{\mathrm{a}} & 3,1 \pm 0,6^{\mathrm{ab}} & 2,3 \pm 0,5^{\mathrm{b}} \\ 4,9 \pm 1,0 & 8,7 \pm 2,3 & 7,8 \pm 0,9 \\ 6,8 \pm 2,3 & 5,5 \pm 1,1 & 5,4 \pm 1,2 \\ 12,3 \pm 2,4^{\mathrm{a}} & 4,3 \pm 0,3^{\mathrm{b}} & 4,7 \pm 1,5^{\mathrm{b}} \\ 31,2 \pm 5,8 & 20,4 \pm 1,5 & 19,5 \pm 0,9\end{array}$

$31,2 \pm 5,8$ 

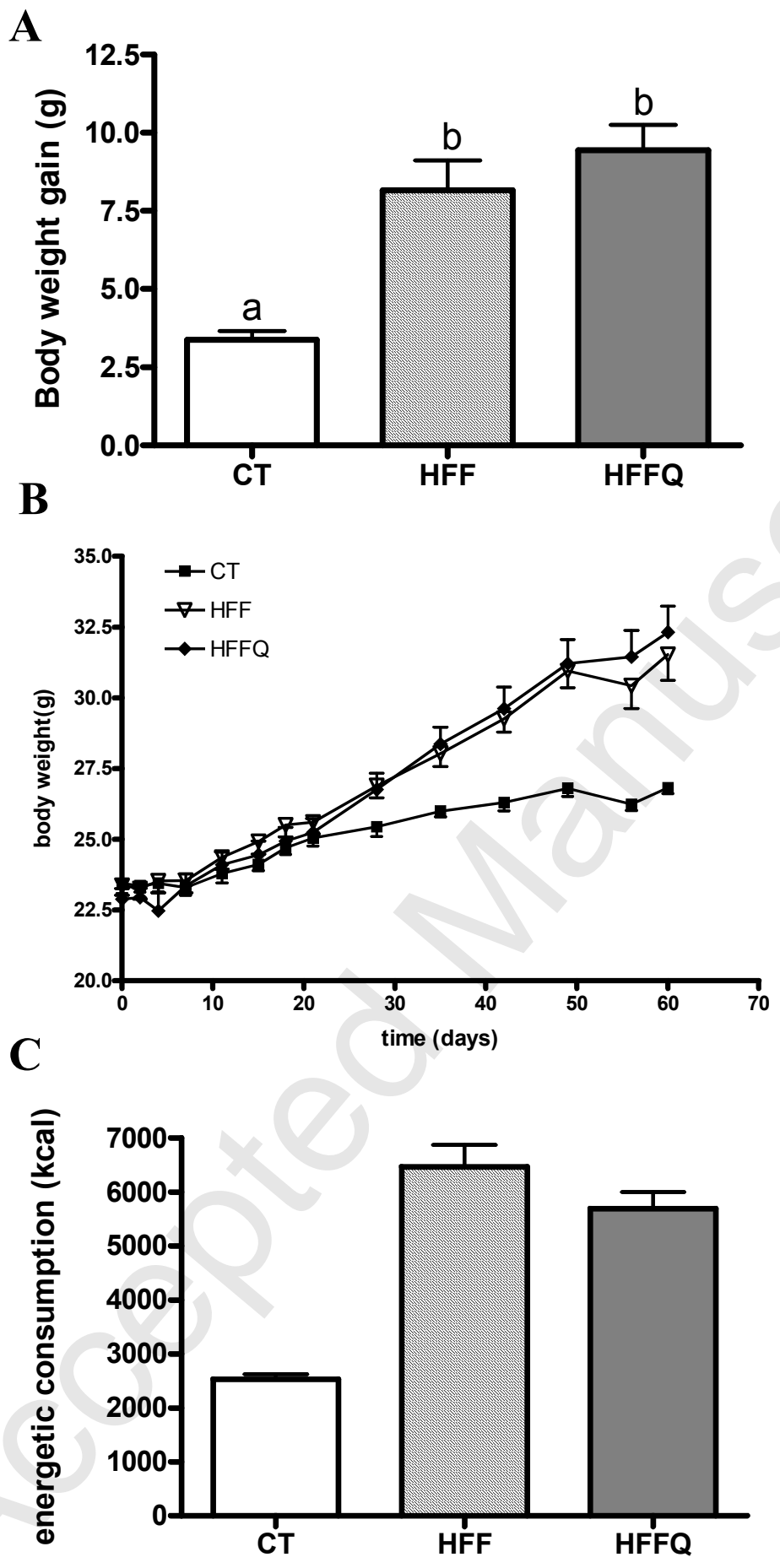


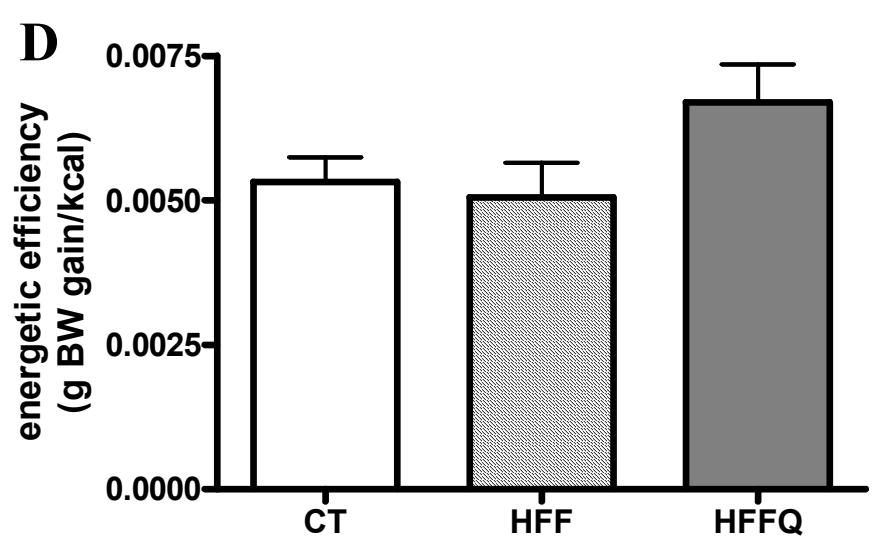

Figure 1 

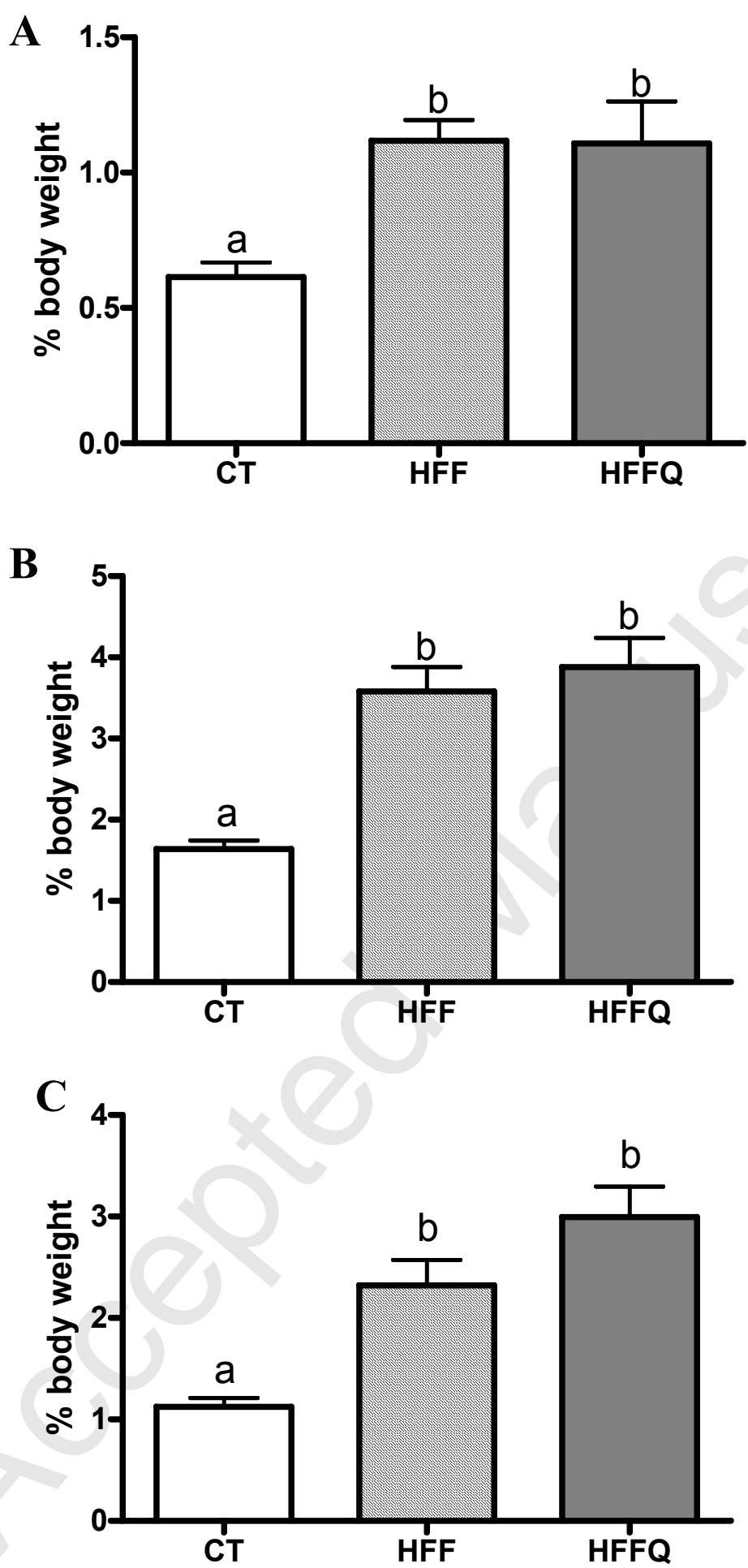

Figure 2 

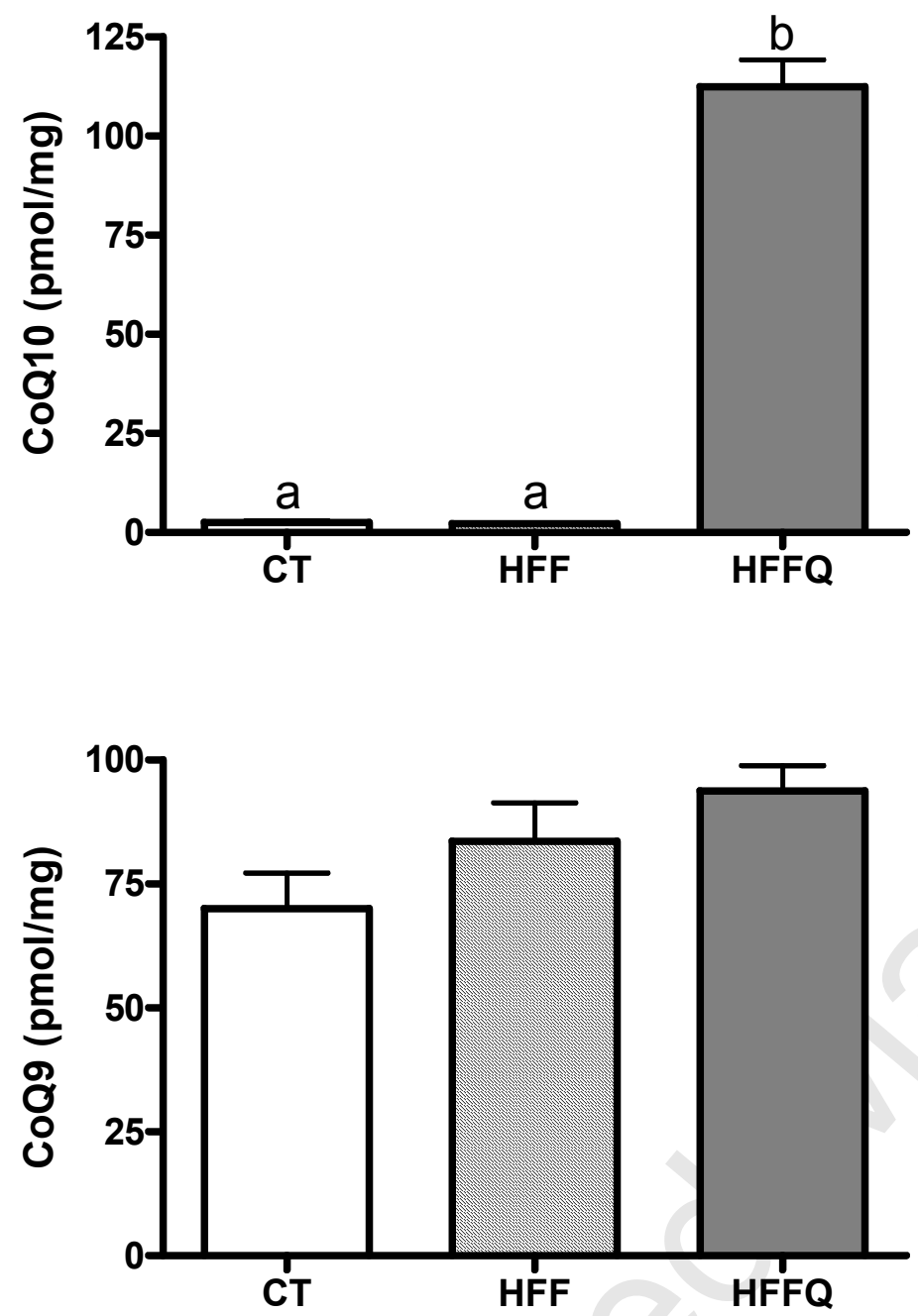

figure 3 

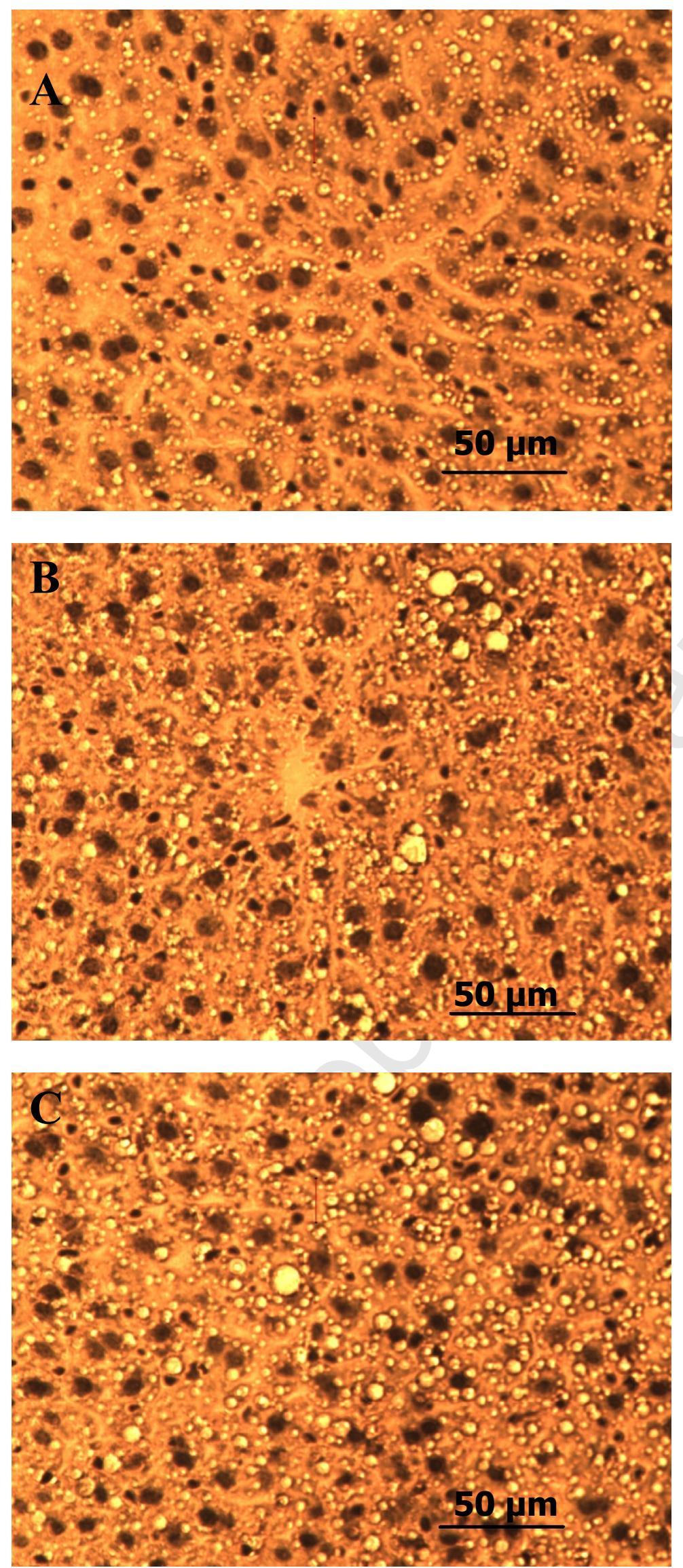

Figure 4 
A
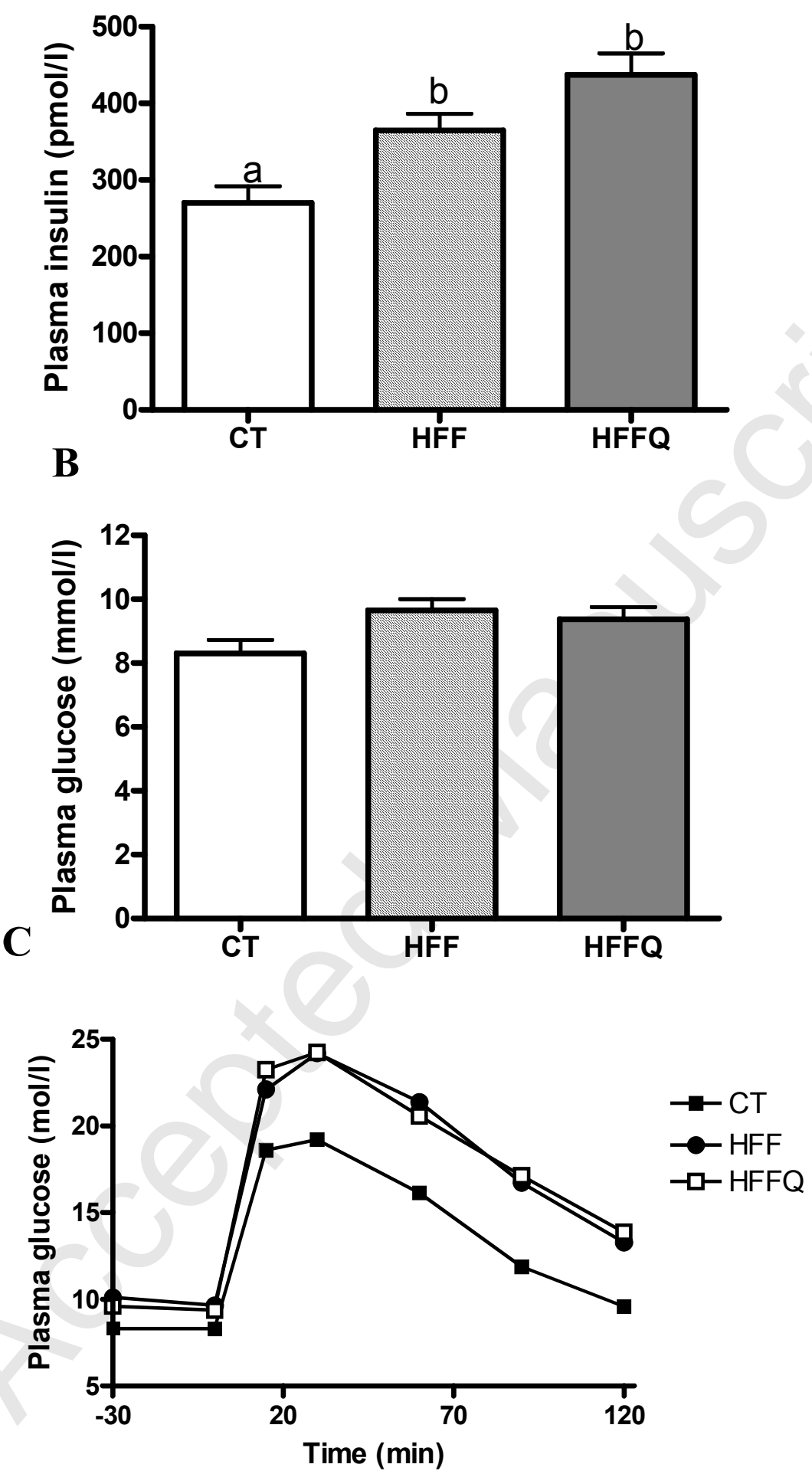

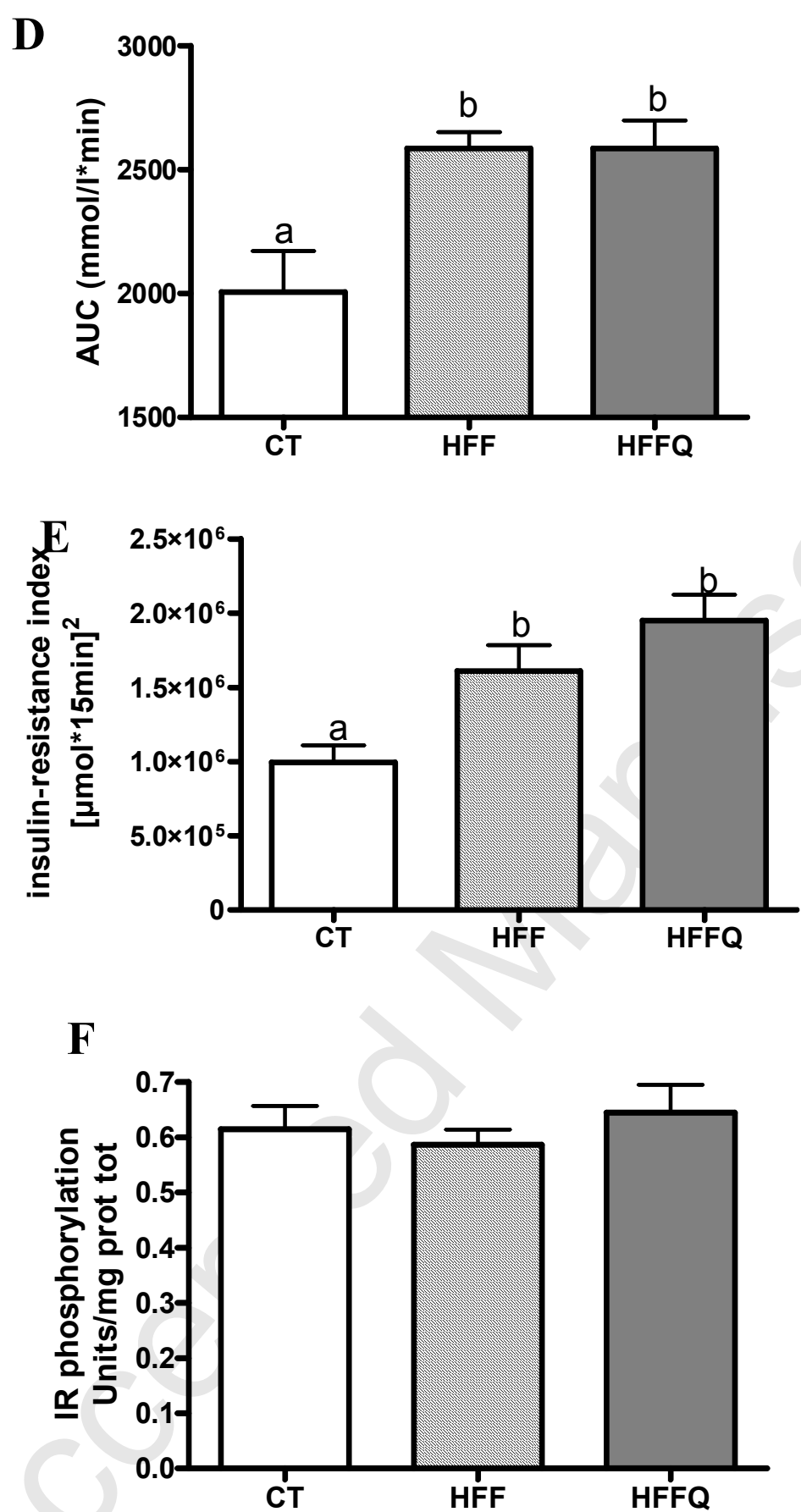

Figure 5 

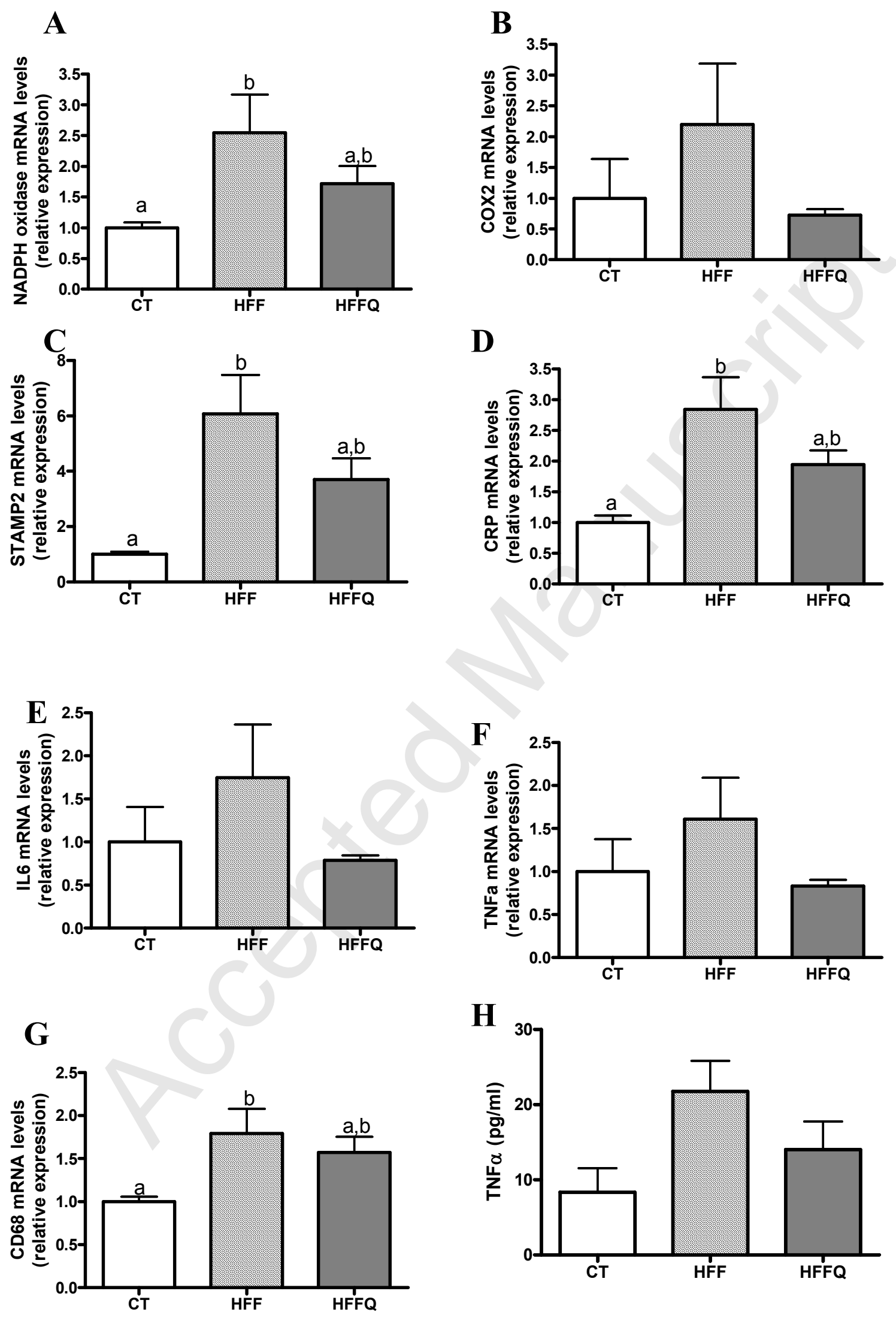


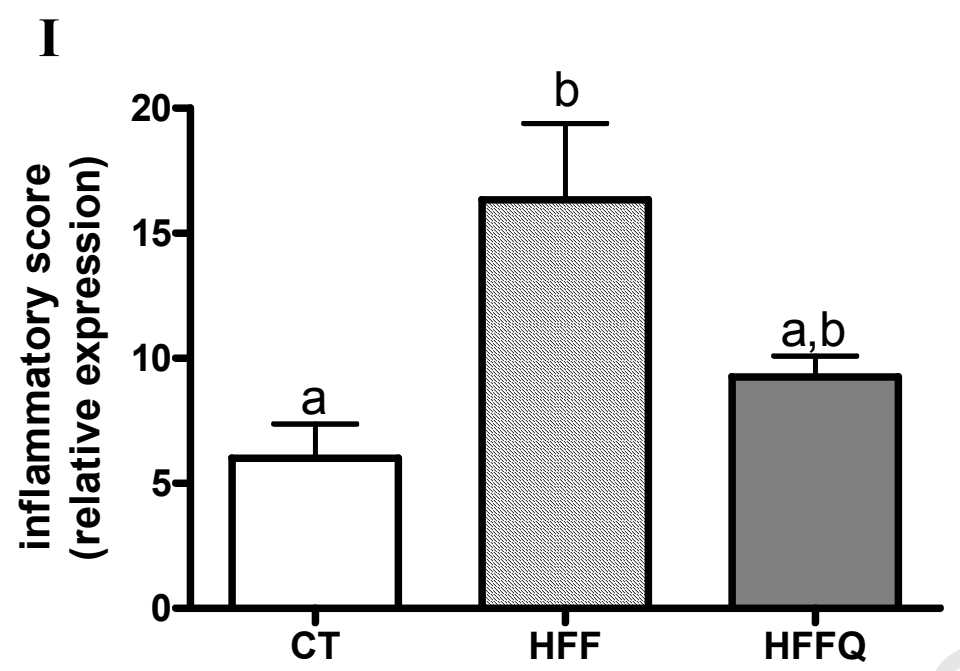

Figure 6 

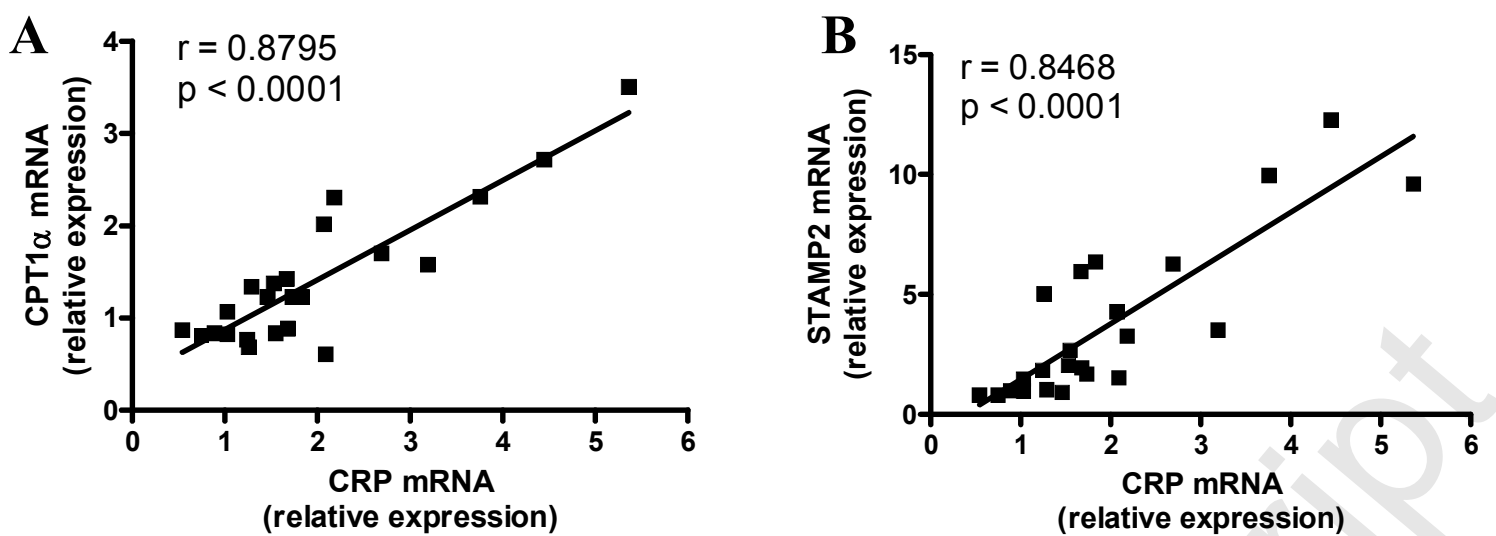

(relative expression)
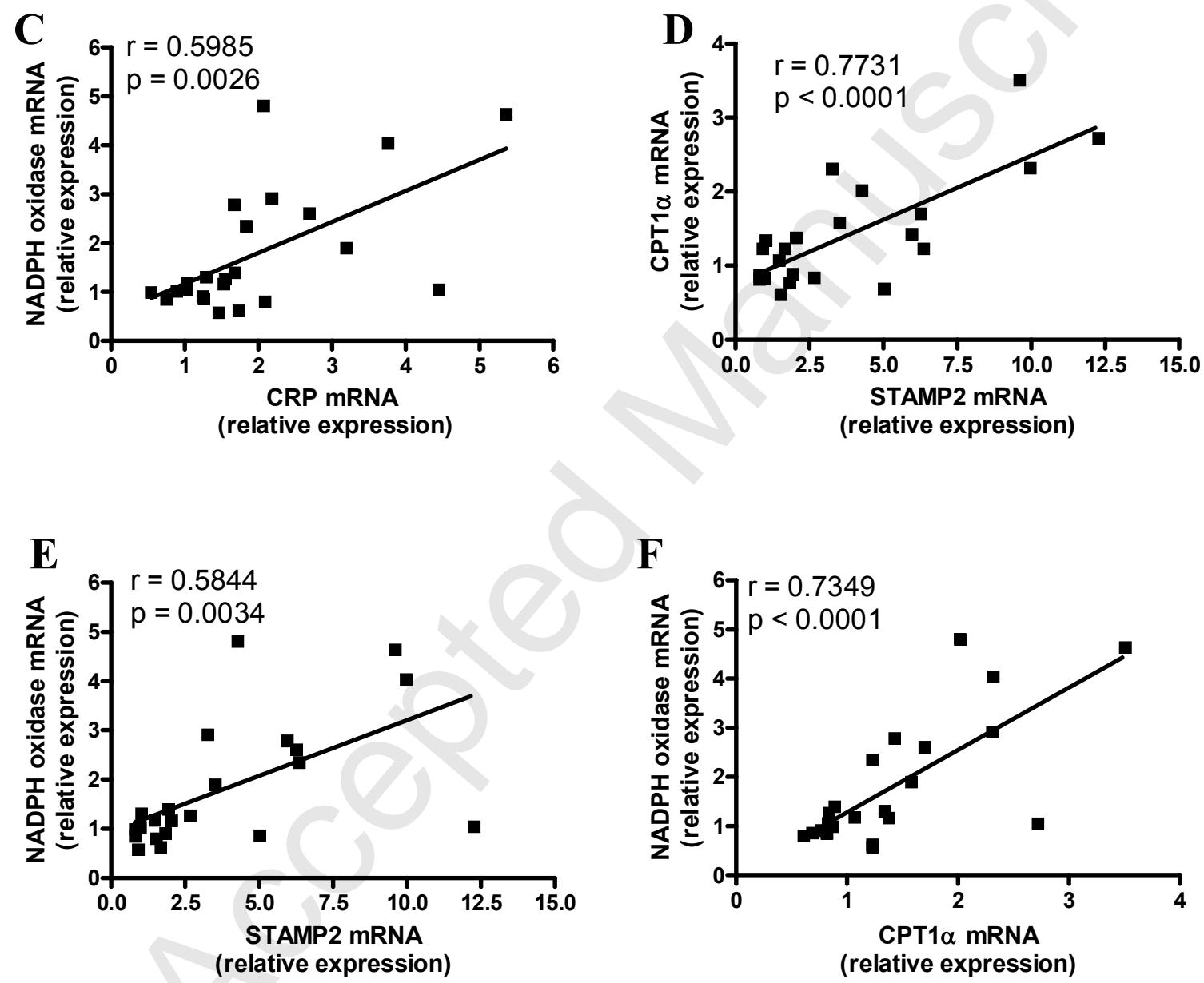

Figure 7 


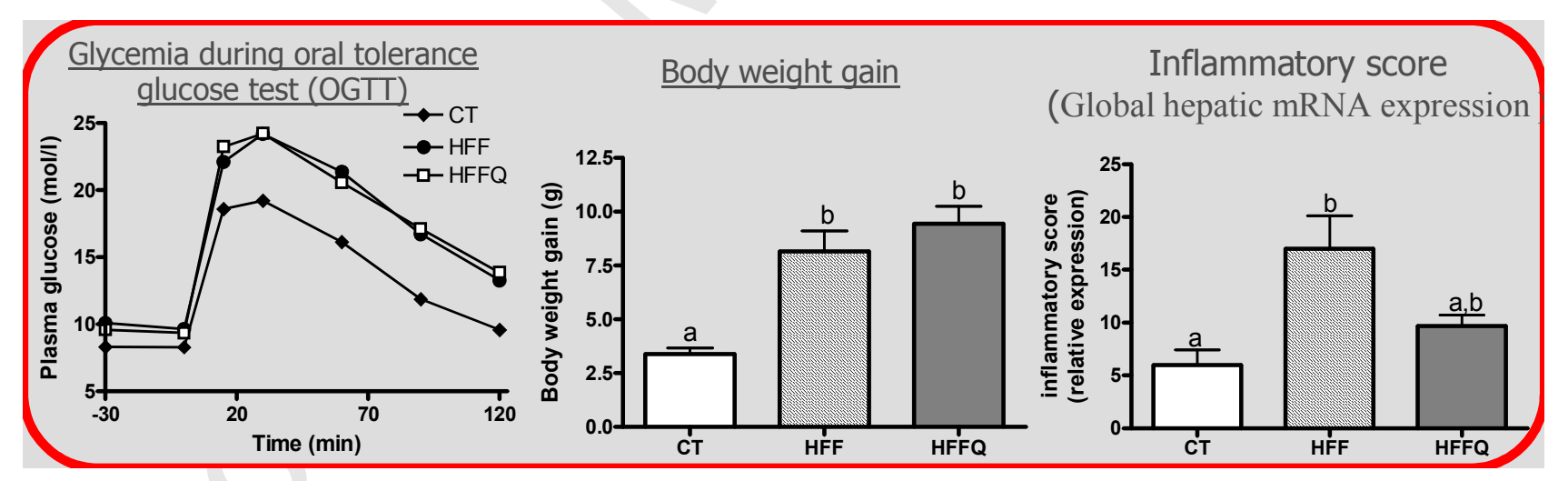

